\title{
0 ponto e a linha na espacialidade lúdica: uma proposta no ensino fundamental
}

\author{
Cláudia Souza de Holleben
}

\begin{abstract}
Este relato visa contribuir para o processo de pesquisa na área de aprendizagem de Arte, na medida em que se desenvolveu através de um projeto baseado em experiências lúdicas que enfocaram a linha e o ponto, como elementos da linguagem visual contextualizados na vida das criancas da Escola Desdobrada Retiro da Lagoa ${ }^{1}$, em Florianópolis SC. 0 trabalho buscou um olhar mais atento às imagens do cotidiano, perpassando a história da arte ao procurar referências na produção de alguns artistas plásticos e sempre propondo práticas que reiterassem este saber.
\end{abstract}

Esta proposta visa defender a importância da ludicidade na educação, principalmente nas séries iniciais, pois acredita-se que o conhecimento possa ser absorvido naturalmente no prazer do lúdico, tornando a aprendizagem significativa por estar vinculada à realidade cognitiva e sensorial da criança.

A escola municipal onde se deu esta experiência é um espaço pequeno e tranqüilo e não conta com professores de Arte na $1^{\text {a }}$ série do ensino fundamental, o que se revelou um dado positivo, justamente pela demonstração de interesse pela troca de experiências.

Através de propostas iniciadas a partir de histórias infantis ou encaminhadas pela exploração sensorial e lúdica, ocorreu o direcionamento no processo de educação estético e artístico, trilhando o caminho que a proposta triangular ${ }^{2}$ oferece de trânsito livre entre contextualização, produção e

1 Localizada à rua Prefeito Acácio G. São Thiago, 201 no bairro Lagoa da Conceição.

2 Encaminhamento pedagógico formulado pela professora Ana Mae Barbosa USP. 
leitura de imagens.

Este direcionamento fez a relação entre a linguagem semi-simbólica (artes plásticas) com a linguagem simbólica (alfabetização), visto que as crianças estavam no início do processo de letramento ${ }^{3}$.

A turma demonstrou alegria e curiosidade ao saber que teriam uma experiência com artes plásticas. Durante a leitura do livro "O menino que aprendeu a ver" as crianças permaneceram atentas, parecendo estar se identificando com a "busca" do menino Joãozinho (personagem principal da história) em decodificar o mundo através dos símbolos gráficos encontrados nos trajetos urbanos. Num segundo momento, a turma recebeu como desafio a proposta de descobrir na letra de "A casa" (música de Vinícius de Moraes), palavras já conhecidas. Para enfatizar o conceito de arte como linguagem, foram estabelecidas algumas relações entre os signos verbais e os não verbais.

Chegamos à conclusão de que, na linguagem escrita, qualquer mudança de posição ou alteração de letra comprometeria o significado da palavra casa, enquanto que, na linguagem plástica, a casa pode ser representada de muitas maneiras. Isto se deu pelo acesso a várias reproduções de casas inseridas na história da arte (utilizando trabalhos de Meyer Filho, Martinho de Haro, Volpi, René Magritte e Paul Klee) e também a imagens fotográficas observadas em livros e revistas. Abriuse o leque de possibilidades no momento da produção, que se deu a partir da proposta de dobrar o papel no meio para, na primeira metade,

3 Identifica o indivíduo que, ao se alfabetizar adquire o estado ou a condição de quem se apropria da leitura e da escrita, incorporando as práticas sociais que as demandam. 
desenhar a sua casa e na outra metade, sobre o mesmo tema, fazer um outro desenho, porém procurando uma forma diversificada de representar. Houve muito empenho na criação das "casas malucas", "casas de pedra", "casas de árvore", "a casa onde moro", "casa bicho", "casa carro", ... Conforme iam finalizando, as crianças se uniam em pequenos grupos para novas apreciações e pesquisas em torno das publicações oferecidas.

No segundo encontro, havia chovido pela manhã e o pátio estava muito molhado. A aula (cujo objetivo era reconhecer a linha como elemento da linguagem visual) foi então adaptada para dentro do espaço da sala. Na primeira proposta cada criança ganhou um pedaço de barbante e após contar para a turma como era seu trajeto de casa até a escola (curto, longo, contendo retas ou muitas curvas), deveria posicionar seu segmento de linha nos corredores entre as mesas da sala.

Quando unidos uns aos outros, estes segmentos formaram um grande trajeto. Depois, em pequenos grupos, as crianças tiveram a oportunidade de percorrer todo o trajeto construído por eles. Num segundo momento as crianças reconheceram o elemento linha em reproduções de obras de artistas como Steinberg, Tarcísio Sapienza, Picasso, Pollock e Paul Klee.

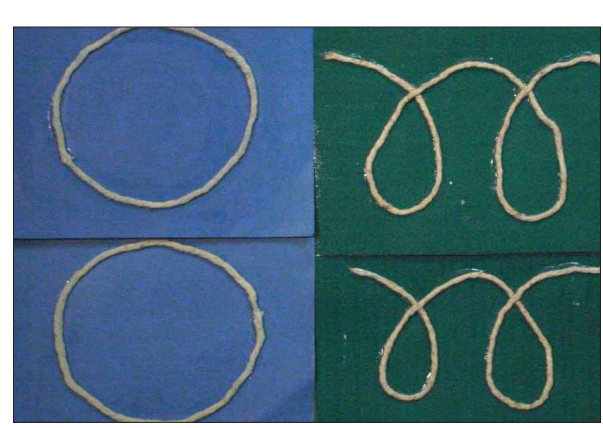

$\mathrm{N}$ a

Jogo de memória

O ponto e a linha na espacialidade lúdica: uma proposta no ensino fundamental 


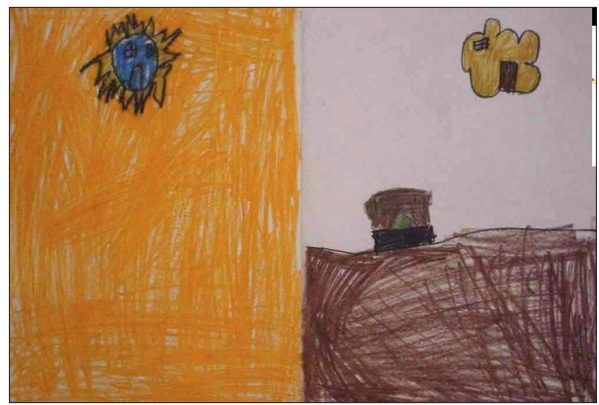

Desenho de Jorge, 7 anos ("Casa Sol”)

proposta seguinte, cada criança recebeu um cartão confeccionado com cordão colado em um suporte representando um tipo de linha (abertas, fechadas, curvas, retas, etc.). Este cartão deveria ficar oculto do restante da turma até que algum colega solicitado viesse a descrever as características idênticas que definisse a linha fixada ali. Como num jogo de memória, a dupla contendo os cartões iguais ia até o centro da sala e unia seus cartões enquanto a turma aplaudia a conquista. Com a ajuda do grande grupo, esta mesma dupla de crianças localizava, nas ilustrações fixadas no mural, artistas que se utilizaram daquele determinado tipo de linha nas suas produções.

Cada criança recebeu um portfólio confeccionado em papel craft no formato de envelope para que suas produções e curiosidades pesquisadas durante $\mathrm{o}$ projeto pudessem ser arquivadas. Então, com o mesmo cordão utilizado para o trajeto, todos puderam 'desenhar' a partir de uma colagem realizada nos portfólios.

Em nosso terceiro encontro, com o objetivo de descobrir a linha no meio ambiente, foi utilizada como recurso a história "O passeio da linha", as

4 Livro-linha de autoria da professora Cláudia Souza de Holleben, confeccionado artesanalmente a partir de uma seqüência fotográfica realizada no trajeto urbano e fixada num rolo de papel. 
crianças demonstraram grande interesse em participar 'desenrolando' a história.

Após, a linha "descolou-se" do papel tornando-se um personagem confeccionado em pano com enchimento de fibra sintética e arame, que foi apresentado às crianças e logo batizado com o nome de "Linha Exibida". Isto se deve ao fato de que ao observar fotografias da cidade de Florianópolis reconheceram múltiplas linhas em suas formas. Esta constatação se estendeu para o ambiente da sala de aula onde a Linha Exibida passeou por muitas 'linhas amigas' enquanto alguns expressavam: - "A Linha Exibida está em toda parte!”

Rolinhos de papel higiênico foram encarados como máquinas fotográficas, e o passeio pela escola foi recheado de descobertas. Muitas linhas foram registradas naquele olhar que se abria prazerosamente para observar o mundo. Isto se refletiu na produção plástica pela naturalidade com que as 'fotos se revelaram' nos desenhos de lápis de cor sobre papel. Num momento posterior, o grupo teve acesso a reproduções fotográficas que registravam trabalhos de Richard Long e outros artistas da Land Art $^{5}$.

Com o objetivo de reconhecer a linha como o ponto em movimento, as crianças, no quarto encontro, ouviram uma história ilustrada em mural com desenhos criados simultaneamente ao relato oral. A história "O nascimento da linha" "não possui um texto fixo e foi contada mais ou menos assim:

“- Vamos fazer de conta que o ponto engordou e virou esta bolinha de gude... 0 menino jogou o

5 Produções artísticas desenvolvidas a partir da paisagem e seus recursos naturais.

6 Autoria da Prof ${ }^{a}$ Cláudia Souza de Holleben. 
ponto, que caiu no mar pegando uma carona com as ondas que subiam e desciam. Até que num impulso, pegou um pé de vento que o fez voar até o sol. Como estava com muito calor, o ponto se jogou lá de cima e caiu numa cidade cheia de prédios muito altos. 0 ponto então, caminhou por cima deles até que encontrou um coelho gigante e azul que o ensinou a pular. Ele pulou, pulou, foi e voltou pulando. Pulou até cansar. Aí se enrolou e rolou até o ponto final. Dormiu, e ponto".

A proposta seguinte foi o Jogo da Bolinha de $G^{\prime} d^{7}$, onde cada criança deveria empurrar uma bolinha sobre um papel A4 utilizando, como instrumento, canetas hidrográficas ou giz de cera. A cor deveria ser modificada quando a bolinha saísse do limite do papel ou caísse no chão.

A história "O nascimento da linha" e o Jogo da Bolinha de Gude serviram como precursores da conversa sobre o pontilhismo ${ }^{8}$ de Seurat. A proposta plástica foi festejada por todos, pois gostam muito do trabalho com tinta guache. Algumas crianças não conseguiram 'segurar a mão' para criar somente através de pontinhos.

Às vezes, as hastes flexíveis, utilizadas como pincel, 'escorregavam um pouquinho' formando pinceladas lineares sobre o papel.

Logo em seguida, ao observar nos cartazes de cinema e em revistas, os pontos que formam cores e texturas, as crianças puderam fazer relações com o pontilhismo e com reproduções de obras da Op Art'.

7 Este jogo foi criado pelo prof. ${ }^{\circ}$ Rosivaldo Flausino.

8 Tecnicamente no pontilhismo, ao invés de misturar os pigmentos para aplicá-los na tela, o pintor (no caso desta pesquisa, Seurat) subdivide as cores em seus componentes, de modo que elas se misturam no olho do observador, quando vistas à distância.

9 Arte abstrata caracterizada pelo preenchimento do plano através de linhas contínuas ou formas geométricas provocando uma ilusão óptica de movimento. 
Cada criança desenhou a silhueta de sua mão e preencheu todo o plano usando, somente, linhas contínuas de várias cores, sempre repetindo o desenho da silhueta. Para isto utilizaram pincel chato e tinta guache.

Num outro momento, as crianças foram convidadas a participar do Jogo dos Elementos Visuais. Cada participante recebeu numa folha o desenho pontilhado de um cubo aberto. A proposta era ligar os pontos utilizando-se de linhas horizontais e verticais. Mas, isto só poderia acontecer se o participante soubesse responder às perguntas ou corresponder a alguns requisitos estipulados pelo grupo.

Após finalizar toda a figura, as crianças conheceram algumas reproduções de Mondrian observando toda a estruturação do plano que utiliza linhas retas horizontais e verticais e cores primárias, além do branco e do preto. A proposta então foi colorir os quadradinhos (o plano) formados pela união das linhas no Jogo dos Elementos Visuais.

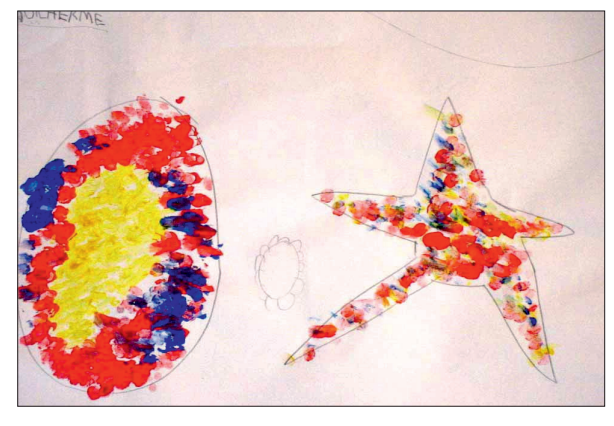

Guilherme, 7 anos 


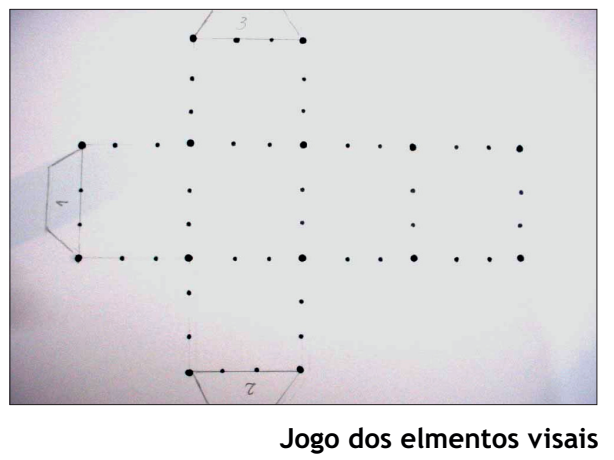

Só então conheceram o trabalho de Hélio Oiticica e seus 'Relevos Espaciais', descobriram o momento em que o plano saiu do bidimensional e chegou no tridimensional, na arte brasileira.

A maneira proposta para que a figura fosse retirada do plano bidimensional foi recortando-a do papel, e, passando-a para o plano tridimensional ao ser dobrada e colada surgindo um sólido geométrico (o cubo), exercício que pontuou o elemento volume na linguagem visual.

Para finalizar a experiência relatada foi confeccionado um bolo em fôrma retangular cuja cobertura de marshmallow foi inserida com saquinho de 'bico de confeiteiro'. A proposta foi um desenho coletivo partindo de um ponto no centro do bolo onde cada criança desenhou o seu segmento de linha em marshmallow até compor um desenho que logo tomou todo o plano do bolo para após ser degustado (volume).

E como diz Roland Barthes: "Sapientia: nenhum poder, um pouco de saber, o máximo de sabor..." (BARTHES apud ALVES, 1995 p.105). 


\section{Referências Bibliográficas}

ALVES, Rubem Azevedo. Conversas com quem gosta de ensinar. São Paulo: Ars Poética, 1995 p.105.

Barbosa, Ana Mãe. Tópicos utópicos. Belo Horizonte: Ed. C/arte, 1998.

ROCHA, Ruth. $O$ menino que aprendeu a ver. $2^{\mathrm{a}}$ ed., São Paulo: Quinteto Editorial, 1998 (Coleção Hora dos Sonhos).

SOARES, Magda. Letramento:um tema para três gêneros. Belo Horizonte, Autêntica, 1998. 